\title{
Foveal processing and word skipping during reading
}

\author{
DENIS DRIEGHE \\ Ghent University, Ghent, Belgium
}

\begin{abstract}
An eyetracking experiment is reported examining the assumption that a word is skipped during sentence reading because parafoveal processing during preceding fixations has reached an advanced level in recognizing that word. Word $n$ was presented with reduced contrast, with case alternation, or normally. Reingold and Rayner (2006) reported that, in comparison to the normal condition, reduced contrast increased viewing times on word $n$ but not on word $n+1$, whereas case alternation increased viewing times on both words. These patterns were reflected in the fixation times of the present experiment, but a striking dissociation was observed in the skipping of word $n+1$ : The reduced contrast of word $n$ decreased skipping of word $n+1$, whereas case alternation did not. Apart from the amount of parafoveal processing, the decision to skip word $n+1$ is also influenced by the ease of processing word $n$ : Difficulties in processing word $n$ lead to a more conservative strategy in the decision to skip word $n+1$.
\end{abstract}

In the past few decades, research on eye movements in reading has produced a vast amount of data and insights into the processing that occurs during reading (for a review, see Rayner, 1998). As a result, many models of the mechanisms underlying eye guidance in reading have been proposed, such as the E-Z Reader model (Pollatsek, Reichle, \& Rayner, 2006; Reichle, Pollatsek, Fisher, \& Rayner, 1998) and the SWIFT model (Engbert, Nuthmann, Richter, \& Kliegl, 2005). In this article, I focus on the following assumption that is incorporated into most of these models: Word skipping during reading is linked tightly to the amount of parafoveal processing that has occurred during the preceding fixation(s). I will do so mostly within the framework of the E-Z Reader model.

E-Z Reader is a quantitative model which assumes that cognitive processes associated with processing the fixated word are the engine behind eye movements in reading. Word recognition is considered to be a serial lexical process under the control of an attentional beam, with the word in the attentional beam being the only word that is being lexically processed. Two phases of word recognition are distinguished. The termination of the first phase $\left(\mathrm{L}_{1}\right)$ cues the oculomotor system to begin programming a saccade to the next word. In the lexical processing of a word, the end of $\mathrm{L}_{1}$ is the point at which the processing system, from prior experience, has learned that it is likely that full word identification will be achieved shortly. The end of the second phase $\left(\mathrm{L}_{2}\right)$ corresponds with full lexical identification, which cues the attentional beam to shift to the next word. This shift usually occurs before the eyes move to the next word, and while the beam is on the parafoveal word (but while the eyes are still on the previous word), parafoveal processing occurs. In this manner, the E-Z Reader model accounts for the parafoveal preview benefit; the finding that a preview of a word to the right of fixation results in shorter fixations on that word when it is subsequently fixated (Rayner, 1975).

As a result of these assumptions, E-Z Reader predicts that manipulations that exclusively disrupt early encoding of visual and orthographic features of the fixated word influence the processing difficulty of word $n$ without disrupting the processing of word $n+1$. That is, if the effect of the experimental manipulation were limited to the $\mathrm{L}_{1}$ phase of word $n$, it would not influence the parafoveal processing of word $n+1$, which is not thought to start until $\mathrm{L}_{2}$ of word $n$ has completed. This hypothesis was tested by Reingold and Rayner (2006) in an experiment where participants read sentences in which one word was presented normally, with case alternation, or with severely reduced contrast. ${ }^{1}$ The condition with the reduced contrast (the faint condition) was assumed to disrupt an early stage in word recognition in which visual features are encoded and abstract letter identities are established (Besner \& Roberts, 2003), whereas case alternation has been shown to influence mostly postencoding lexical processing (Herdman, Chernecki, \& Norris, 1999). The results were straightforward and consistent with the E-Z Reader prediction: Whereas the faint condition resulted in longer fixation times on word $n$, the fixation times on word $n+1$ did not differ significantly between the faint and the normal conditions. The case alternation condition showed slightly longer fixation times on word $n$ than did the normal condition (and showed shorter fixation times than did the faint condition) but did cause the fixation

D. Drieghe, denis.drieghe@ugent.be 
times on word $n+1$ to be significantly longer than those for the normal condition.

In E-Z Reader, word skipping is based on the following sequence of events: If (1) the eyes are on word $n$, (2) the attentional beam has shifted to word $n+1$, and (3) the first phase of the identification of word $n+1$ in the parafovea is rapid enough, the programming of the eye movement to word $n+1$ is cancelled and replaced by the programming of a saccade to word $n+2$. As a consequence, word $n+1$ is skipped. Critically, E-Z Reader states that a word is skipped because it is recognized in parafoveal vision, or more precisely, that recognition is imminent. Thus, it follows that the chances of recognizing, and skipping, the parafoveal word would be reduced when the amount of parafoveal preview is reduced. The amount of parafoveal processing is influenced by the duration of the $\mathrm{L}_{2}$ phase on word $n$ : The saccade programming starts after $\mathrm{L}_{1}$ is concluded and lasts a relatively constant amount of time. As a consequence, a short $\mathrm{L}_{2}$ phase leads to more parafoveal processing of word $n+1$ than does a long $\mathrm{L}_{2}$ phase. Indeed, this is how the E-Z Reader model accounts for the finding that the parafoveal preview benefit is reduced after a low-frequency word as compared with after a high-frequency word (Henderson \& Ferreira, 1990).

The aim of the present experiment was to see whether the link between the amount of parafoveal processing and the skipping rate of word $n+1$ is indeed as tight as is assumed by the E-Z Reader model. If so, one would expect a condition that does not affect the $\mathrm{L}_{2}$ phase of word $n$ (i.e., the faint condition of Reingold \& Rayner, 2006) to lead to skipping rates of word $n+1$ comparable to those in the normal condition. A condition that increases the $\mathrm{L}_{2}$ phase of word $n$, such as the case alternation condition, would decrease parafoveal processing and, as a consequence, lower skipping rates of word $n+1$.

There was another reason for running this experiment: Fixation durations on word $n+1$ and the skipping of word $n+1$ are usually considered as correlated measures of the same phenomenon: the amount of preceding parafoveal processing. However, although a study looking directly at the effects of foveal word frequency on the skipping of either a correct or an incorrect parafoveal preview of a three-letter word did show a main effect of foveal load (less skipping after a low-frequency word) and preview (the incorrect preview was skipped less often), the crucial interaction, indicating the influence of the amount of parafoveal processing on word skipping, was absent (Drieghe, Rayner, \& Pollatsek, 2005). This interaction has been observed multiple times on the fixation duration of word $n+1$ (e.g., Henderson \& Ferreira, 1990), warranting a closer examination of the link between these two measures.

Prior research has shown that skipping rates tend to be higher for short words than for long words and for highfrequency words than for low-frequency words (for a review, see Brysbaert, Drieghe, \& Vitu, 2005). Therefore, in order to have high enough skipping rates to detect any potential effects, word $n+1$ was a short, very frequent word in the present study.

\section{METHOD}

\section{Participants}

Thirty Ghent University students, who were native speakers of Dutch with normal or corrected-to-normal vision, were paid $€ 8$ to participate in the experiment.

\section{Apparatus}

Eye movements were measured with an SR Research EyeLink 1000 system. Viewing was binocular, but eye movements were recorded from the right eye only. Following calibration, gaze position error was less than $0.5^{\circ}$. Fixation locations were sampled every millisecond. All sentences were displayed on a single line, and all letters were lowercase (except when capitals were appropriate) and in monospaced Courier font. The text was presented in black $\left(0.5 \mathrm{~cd} / \mathrm{m}^{2}\right)$ on a white background $\left(97 \mathrm{~cd} / \mathrm{m}^{2}\right)$. The average brightness of word $n$ in the faint condition was $86 \mathrm{~cd} / \mathrm{m}^{2}$. The display was $60 \mathrm{~cm}$ from the participant's eye, and 2.4 characters equaled $1^{\circ}$ of visual angle.

\section{Materials}

Seventy-two sentences were created so that every sentence featured the following succession: word $n$, which was five letters long, and word $n+1$, which in half of the sentences was three letters long and in the other half was four letters long. The average frequency was 551 per million for word $n$ and 2,834 per million for word $n+1$ (Baayen, Piepenbrock, \& van Rijn, 1993). Two additional conditions were created by modifying word $n$ : It was presented with case alternation or shown with reduced contrast. A counterbalanced design was employed in which each of the 72 sentences was read only once by each participant, resulting in 24 sentences per condition per participant.

\section{Procedure}

Participants were given a description of the experimental procedure and were asked to read the sentences on the monitor. They were told that they would be asked questions about the sentences and were instructed to read for comprehension. Participants stopped sentence presentation by pressing a button. The initial calibration of the eyetracking system required about $5 \mathrm{~min}$. Each participant read 12 practice sentences, of which 4 featured a case alternation word, 4 featured a reduced-contrast word, and 4 were unmodified. Comprehension questions were asked after $25 \%$ of the trials; accuracy answering them was $95 \%$. The experiment lasted about $25 \mathrm{~min}$.

\section{RESULTS}

Fixation durations shorter than $100 \mathrm{msec}$ and longer than $1,200 \mathrm{msec}$ were removed from the analyses. Three eye movement measures were computed. First fixation duration is the duration of the first fixation on a word; single fixation duration refers to when only one fixation is made on the word; and gaze duration is the sum of all fixations on a word prior to moving to the next. Trials on which the eyetracker lost track of the eye position were removed. As a result, about $0.3 \%$ of the trials were excluded from the analyses. After the computation of the skipping percentages of word $n$, an additional $27 \%$ of the trials were removed from the analyses of the other eye movement measures for one of the following two reasons: (1) Word $n$ was skipped (19.8\% of the trials), or (2) the participant made a regression from word $n(7.4 \%$ of the trials). A series of repeated measures ANOVAs were undertaken with participants $\left(F_{1}\right)$ and items $\left(F_{2}\right)$ as random variables. All of the reported $p$ values for the contrasts were Bonferroni adjusted. 


\section{Skipping of Word $n$}

The skipping probabilities associated with word $n$ are shown in Table 1. The typographical modifications of word $n$ exerted a significant influence on the skipping rates $\left[F_{1}(2,58)=8.33, p<.001 ; F_{2}(2,142)=14.19, p<\right.$ $.001]$. Contrasts showed that word $n$ was skipped $6 \%$ more often in the normal condition than in the faint condition, which in turn was skipped $7 \%$ more often than word $n$ in the case alternation condition, although some $p$ values in the participants analysis were no longer significant after Bonferroni corrections [normal vs. case alternation, $t_{1}(29)=5.13, p<.001 ; t_{2}(71)=5.21, p<.001$; normal vs. faint, $t_{1}(29)=1.81, p>.10 ; t_{2}(71)=2.57, p<$ .05 ; case alternation vs. faint, $t_{1}(29)=-1.96, p>.10$; $\left.t_{2}(71)=-2.83, p<.05\right]$

\section{Fixation Times on Word $n$}

The fixation times on word $n$ are shown in Table 1. All measures show the same pattern: The normal condition is associated with the shortest fixation times, and dramatically longer fixation times are observed in the faint condition. The manipulation of word $n$ was significant in the analysis of the first fixation durations $\left[F_{1}(2,58)=106.85, p<.001 ; F_{2}(2,142)=242.26\right.$, $p<.001]$. Contrasts showed that the first fixation duration in the faint condition was $127 \mathrm{msec}$ longer than it was in the case alternation condition, which in turn was read 12 msec slower than it was in the normal condition [normal vs. case alternation, $t_{1}(29)=-3.00, p<$ $.05 ; t_{2}(71)=-3.01, p<.05$; normal vs. faint, $t_{1}(29)=$ $-10.35, p<.001 ; t_{2}(71)=-17.56, p<.001$; case alternation vs. faint, $t_{1}(29)=-10.35, p<.001 ; t_{2}(71)=$ $-15.58, p<.001]$. The manipulation of word $n$ was also significant for the single fixation duration $\left[F_{1}(2,58)=\right.$ $\left.75.01, p<.001 ; F_{2}(2,142)=194.40, p<.001\right]$, which was $174 \mathrm{msec}$ longer in the faint condition than in the case alternation condition. The case alternation condition received single fixation durations $12 \mathrm{msec}$ longer than did the normal condition [normal vs. case alternation, $t_{1}(29)=-2.38, p<.10 ; t_{2}(71)=-3.29, p<.01$; normal vs. faint, $t_{1}(29)=-8.97, p<.001 ; t_{2}(71)=-15.20$, $p<.001$; case alternation vs. faint, $t_{1}(29)=-8.57, p<$ $\left..001 ; t_{2}(71)=-13.74, p<.001\right]$. Finally, the effect of the typographical manipulations was also significant in the analyses of the gaze durations $\left[F_{1}(2,58)=87.62, p<\right.$ $\left..001 ; F_{2}(2,142)=486.38, p<.001\right]$. The gaze duration was $264 \mathrm{msec}$ longer in the faint condition than in the case alternation condition, in which in turn it was $23 \mathrm{msec}$ longer than in the normal condition [normal vs. case alternation, $t_{1}(29)=-3.47, p<.01 ; t_{2}(71)=-3.60, p<$ .01 ; normal vs. faint, $t_{1}(29)=-9.70, p<.001 ; t_{2}(71)=$ $-25.85, p<.001$; case alternation vs. faint, $t_{1}(29)=$ $\left.-9.20, p<.001 ; t_{2}(71)=-21.25, p<.001\right] .^{2}$

\section{Skipping of Word $n+1$}

The skipping probabilities associated with word $n+1$ are shown in Table 1 . The modifications of word $n$ resulted in a significant effect on the skipping of word $n+1$ $\left[F_{1}(2,58)=6.78, p<.01 ; F_{2}(2,142)=12.04, p<.001\right]$. Contrasts showed that this was entirely due to the skipping of word $n+1$ in the faint condition, which happened on average $12 \%$ less often than in the other two conditions [normal vs. case alternation, all $t \mathrm{~s}<1$, n.s.; normal vs. faint, $t_{1}(29)=2.73, p<.05 ; t_{2}(71)=3.54, p<.01$; case alternation vs. faint, $t_{1}(29)=3.38, p<.01 ; t_{2}(71)=$ $4.81, p<.001]$. Because word skipping is influenced strongly by word length, an extra ANOVA was run with word length as a factor. The skipping rates of word $n+1$ computed separately for the three- and four-letter words are also shown in Table 1 . The main effect of word length was significant $\left[F_{1}(1,29)=53.85, p<.001 ; F_{2}(1,35)=\right.$ $37.48, p<.001]$. Three-letter words were skipped on average $18 \%$ more often than four-letter words. The main effect of the manipulation of word $n$ was also significant $\left[F_{1}(2,58)=6.77, p<.01 ; F_{2}(2,70)=10.82, p<.001\right]$. Again this effect was caused by the skipping probabilities of the faint condition being lower than in the other two conditions [normal vs. case alternation, $F_{1}(1,29)<1$, n.s.; $F_{2}(1,35)=1.06, p>.20$; normal vs. faint, $F_{1}(1,29)=$ $8.18, p<.05 ; F_{2}(1,35)=8.85, p<.05$; case alternation vs. faint, $F_{1}(1,29)=9.98, p<.05 ; F_{2}(1,35)=24.02, p<$ $.001]$. There was no interaction between word length and the typographical manipulations (all $F_{\mathrm{s}}<1$, n.s.).

\section{Fixation Times on Word $n+1$}

It is important to stress here that the present experiment was designed specifically for examining the effects of the typographical manipulations on the skipping of word $n+1$ (i.e., by using short, frequent words), and as a consequence it was less suited for the analysis of the fixation times on word $n+1$. This was so for two reasons: (1) Because very short words were used as word $n+1$ to elicit as much skipping as possible, the amount of data of the fixation times on word $n+1$ is limited, and (2) when short words are skipped very often, the effects can be polluted by "mislocated fixations" (see Drieghe, Rayner, \&

Table 1

Probability of Skipping (Skip) Word $n$, Viewing Times on Word $n$ (in Milliseconds), and Probability of Skipping Word $n+1$ for All Word Lengths and Restricted to the Three- and Four-Letter Words

\begin{tabular}{|c|c|c|c|c|c|c|c|}
\hline & \multicolumn{4}{|c|}{ Word $n$} & \multicolumn{3}{|c|}{ Word $n+1$ Skip } \\
\hline & Skip & $\begin{array}{c}\text { First } \\
\text { Fixation } \\
\text { Duration }\end{array}$ & $\begin{array}{c}\text { Single } \\
\text { Fixation } \\
\text { Duration }\end{array}$ & $\begin{array}{c}\text { Gaze } \\
\text { Duration }\end{array}$ & All & $\begin{array}{l}\text { Three- } \\
\text { Letter } \\
\text { Word }\end{array}$ & $\begin{array}{l}\text { Four- } \\
\text { Letter } \\
\text { Word }\end{array}$ \\
\hline Normal & .26 & 197 & 199 & 209 & .61 & .72 & .52 \\
\hline Case alternation & .13 & 209 & 211 & 232 & .62 & .69 & .53 \\
\hline Faint & .20 & 336 & 385 & 496 & .50 & .59 & .41 \\
\hline
\end{tabular}


Pollatsek, 2008; Nuthmann, Engbert, \& Kliegl, 2005). That is, there are discrepancies between where a saccade is targeted and where it lands. For a very short word, this can quite often lead to an unintentional landing on or skipping of the word, which influences the fixation times on the word and can even lead to patterns other than those typically observed for longer words. As is apparent from the fixation times shown in Table 2, the patterns observed on word $n+1$ were quite different depending on the word length of word $n+1$, so the analysis of the fixation times will be presented separately for three- and for four-letter words.

Because the three-letter word was skipped so often, the amount of data caused the fixation times on word $n+1$ to be not very informative. Indeed, no significant effects were observed from the typographical manipulation of word $n$ on any of the fixation time measures on the three-letter word $n+1$ [first fixation duration, $F_{1}(2,38)=1.06, p>$ $.20 ; F_{2}<1$, n.s.; single fixation duration, all $F_{\mathrm{S}}<1$, n.s.; gaze duration, all $F \mathrm{~s}<1$, n.s.]. A somewhat clearer picture emerged from the fixation times on the four-letter word $n+1$. The manipulation on word $n$ had a marginally significant effect on the first fixation durations on word $n+1\left[F_{1}(2,44)=2.52, p<.10 ; F_{2}(2,66)=3.48, p<\right.$ $.05]{ }^{3}$ A similar picture emerged from the analysis of the single fixation durations on word $n+1$ : The effect of the manipulation on word $n$ was marginally significant in the items analysis $\left[F_{1}(2,44)=1.41, p>.20 ; F_{2}(2,66)=2.90\right.$, $p>.05]$. Note that the first and single fixation durations in the faint condition seem somewhat shorter than in the normal condition. This is contrary to the Reingold and Rayner (2006) data, which showed slightly longer (also nonsignificant) observations for these measures. Whereas this difference could have been due to the higher skipping rates in the present study, resulting in more pollution by mislocated fixations, the statistical nonsignificance of these observations in both studies prevents the drawing of any conclusions. Finally, the gaze duration on word $n+1$ also showed a marginally significant effect of the manipulation on word $n$ in the item analyses $\left[F_{1}(2,44)=1.41, p>.20\right.$; $\left.F_{2}(2,66)=2.90, p>.05\right]$. Because in the gaze duration data, the pattern reported by Reingold and Rayner quite strongly emerged in the means, an extra contrast was carried out, testing directly whether the gaze duration was longer in the case alternation condition than in the other two conditions. This contrast was only marginally significant $\left[F_{1}(1,22)=2.73, p=.11 ; F_{2}(1,33)=3.58, p=.06\right]$.
In summary, even though neither the design of the experiment nor the amount of data allows us to draw strong conclusions about the fixation times on word $n+1$, one can consider the fixation times to be compatible with those reported by Reingold and Rayner (2006): In the analysis restricted to the stimuli where some statistical power was involved (i.e., the four-letter words), the case alternation condition was associated consistently with the longest fixation times. This is corroborated by the fact that, in the measure presumably least infected by mislocated fixations (i.e., the gaze duration analysis), a marginally significant effect of the case alternation condition emerged, with an effect size (on average $17 \mathrm{msec}$ longer than the other two conditions) very closely resembling the effect size observed by Reingold and Rayner.

\section{DISCUSSION}

Reingold and Rayner (2006) tested the E-Z Reader model's prediction that manipulations that disrupt early encoding of visual and orthographic features but not the ensuing lexical processing of word $n$ would influence the fixation times on word $n$ but not on word $n+1$. Indeed, they observed that reducing the contrast of word $n$ led to increased fixation times on word $n$ but did not change the fixation times on word $n+1$. The case alternation manipulation, which disrupts postencoding lexical processing, resulted in longer fixation times on both word $n$ and word $n+1$. Whereas these patterns were also reflected in the present study in the fixation times on word $n$ andnot significantly — on word $n+1$, a different pattern was observed in the skipping rates for word $n+1$ : The faint condition reduced skipping of word $n+1$, and there was no difference between the case alternation and the normal condition. Although the lack of a difference in skipping rate between the case alternation and the normal condition might have been due to ceiling effects (skipping rates were very high in both conditions), this cannot explain the effect observed in the faint condition.

On the basis of the assumption that fixation times and skipping rates would both be reflections of the same phenomenon (i.e., amount of parafoveal processing), comparable patterns were expected in both measurements. This was clearly not the case. To interpret this surprising finding, it is important to note that the skipping rates for word $n+1$ reflect the effects observed in the fixation times on word $n$. The condition with the longest fixation times,

Table 2

First Fixation Duration, Single Fixation Duration, and Gaze Duration (in Milliseconds) on Word $n+1$ for the Three- and Four-Letter Words

\begin{tabular}{|c|c|c|c|c|c|c|}
\hline & \multicolumn{6}{|c|}{ Word $n+1$} \\
\hline & \multicolumn{3}{|c|}{ Three-Letter Word } & \multicolumn{3}{|c|}{ Four-Letter Word } \\
\hline & $\begin{array}{c}\text { First } \\
\text { Fixation } \\
\text { Duration }\end{array}$ & $\begin{array}{c}\text { Single } \\
\text { Fixation } \\
\text { Duration }\end{array}$ & $\begin{array}{c}\text { Gaze } \\
\text { Duration }\end{array}$ & $\begin{array}{c}\text { First } \\
\text { Fixation } \\
\text { Duration }\end{array}$ & $\begin{array}{c}\text { Single } \\
\text { Fixation } \\
\text { Duration }\end{array}$ & $\begin{array}{c}\text { Gaze } \\
\text { Duration }\end{array}$ \\
\hline Normal & 197 & 202 & 205 & 204 & 204 & 205 \\
\hline Case alternation & 182 & 183 & 189 & 208 & 207 & 220 \\
\hline Faint & 201 & 202 & 204 & 190 & 192 & 201 \\
\hline
\end{tabular}


the faint condition, was also the condition with the lowest skipping rates on word $n+1$. This makes sense if one views skipping as a mechanism that consists of cancelling the planned saccade to the next word, a mechanism that the eye guidance system uses only when all indications point in the direction that skipping the following word will not impede reading rate or hinder text understanding. The novel thing here is that skipping is not influenced exclusively by the amount of parafoveal processing, but also by the ease of foveal processing. Put differently, a difficult foveal word - even when the difficulty is limited to the $\mathrm{L}_{1}$ stage as it is perceived by the E-Z Reader model — causes the system to adopt a more conservative strategy in deciding whether to skip the next word.

Alternatively, one could consider the present results as arguing against the purity of the faint condition as a manipulation that exclusively affects early stages of word recognition. Whereas this possibility cannot be ruled out, it is unlikely that any disruption in the later stages of the processing of word $n$ would result in the short fixation durations observed on word $n+1$.

The present findings are compatible with the results reported by Drieghe et al. (2005), who examined the influence of foveal load on the skipping of the next word (see also White, 2007). They observed that a low-frequency word $n$ led to reduced skipping of word $n+1$ and that an incorrect parafoveal preview was skipped less often than a correct preview, but these two effects did not interact. Clearly, the decision to skip word $n+1$ is influenced by more factors than the amount of parafoveal processing. The ease of processing of word $n$ also influences this decision. As such, the conclusions of this study suggest that some modification is needed in the current implementation of the E-Z Reader model.

\section{AUTHOR NOTE}

D.D. is a postdoctoral fellow of the Fund for Scientific Research (Flanders, Belgium). I thank Keith Rayner for discussions concerning the manuscript and Reinhold Kliegl, Eyal Reingold, and an anonymous reviewer for their helpful critiques on a previous draft. Correspondence should be sent to D. Drieghe, Department of Experimental Psychology, Ghent University, Henri Dunantlaan 2, B-9000 Ghent, Belgium (e-mail: denis.drieghe@ugent.be).

\section{REFERENCES}

BaAyen, R. H., Piepenbrock, R., \& van Rijn, H. (1993). The CELEX Lexical Database (Release 1) [CD-ROM]. Philadelphia: Linguistic Data Consortium, University of Pennsylvania.

Besner, D., \& Roberts, M. A. (2003). Reading nonwords aloud: Results requiring change in the dual route cascaded model. Psychonomic Bulletin \& Review, 10, 398-404.

Brysbaert, M., Drieghe, D., \& Vitu, F. (2005). Word skipping: Implications for theories of eye movement control in reading. In G. Under- wood (Ed.), Cognitive processes in eye guidance (pp. 53-77). Oxford: Oxford University Press.

Drieghe, D., Rayner, K., \& Pollatsek, A. (2005). Eye movements and word skipping during reading revisited. Journal of Experimental Psychology: Human Perception \& Performance, 31, 954-969.

Drieghe, D., Rayner, K., \& Pollatsek, A. (2008). Mislocated fixations can account for parafoveal-on-foveal effects in eye movements during reading. Quarterly Journal of Experimental Psychology, 61, 1239-1249.

Engbert, R., Nuthmann, A., Richter, E. M., \& Kliegl, R. (2005). SWIFT: A dynamical model of saccade generation during reading. Psychological Review, 112, 777-813.

Henderson, J. M., \& Ferreira, F. (1990). Effects of foveal processing difficulty on the perceptual span in reading: Implications for attention and eye movement control. Journal of Experimental Psychology: Learning, Memory, \& Cognition, 16, 417-429.

Herdman, C. M., Chernecki, D., \& Norris, D. (1999). Naming cAsE aLtErNaTeD words. Memory \& Cognition, 27, 254-266.

KLIEGL, R., \& ENGBERT, R. (2005). Fixation durations before word skipping in reading. Psychonomic Bulletin \& Review, 12, 132-138.

Nuthmann, A., Engbert, R., \& Kliegl, R. (2005). Mislocated fixations during reading and the inverted optimal viewing position effect. Vision Research, 45, 2201-2217.

Pollatsek, A., Reichle, E. D., \& Rayner, K. (2006). Tests of the E-Z Reader model: Exploring the interface between cognition and eyemovement control. Cognitive Psychology, 52, 1-56.

RAYNER, K. (1975). The perceptual span and peripheral cues in reading. Cognitive Psychology, 7, 65-81.

RAYNER, K. (1998). Eye movements in reading and information processing: 20 years of research. Psychological Bulletin, 124, 372-422.

Reichle, E. D., Pollatsek, A., Fisher, D. L., \& Rayner, K. (1998). Toward a model of eye movement control in reading. Psychological Review, 105, 125-157.

REINGOLD, E. M., \& RAYNER, K. (2006). Examining the word identification stages hypothesized by the E-Z Reader model. Psychological Science, 17, 742-746.

White, S. J. (2007). Foveal load and parafoveal processing: The case of word skipping. In R. P. G. van Gompel, M. H. Fischer, W. S. Murray, \& R. L. Hill (Eds.), Eye movements: A window on mind and brain (pp. 409-424). Amsterdam: Elsevier.

\section{NOTES}

1. Reingold and Rayner (2006) also had a condition that presented word $n$ in boldface. Like the case alternation condition, this condition was assumed to affect postlexical processing and influenced fixation times in a fashion similar to that for the case alternation condition.

2. Because E-Z Reader states that a word is skipped by cancelling the saccade to the skipped word, it predicts an inflated fixation duration prior to skipping (for a discussion, see Kliegl \& Engbert, 2005). Controlling for launch position by restricting the analysis to single fixations on word $n$, no differences were observed between the fixation duration prior to skipping or landing on word $n+1$ in the normal condition [198 msec prior to skipping vs. $201 \mathrm{msec}$ prior to landing; $\left.t_{1}(28)<1 ; t_{2}(62)=-1.15, p>.20\right]$, the case alternation condition $\left[212\right.$ vs. $\left.207 \mathrm{msec} ; t_{1}(26)=1.26, p>.20 ; t_{2}(64)<1\right]$, or the faint condition [383 vs. $\left.393 \mathrm{msec} ; t_{1}(24)<1 ; t_{2}(50)=1.805, p>.05\right]$.

3. Contrasts were carried out for all comparisons between conditions. However, none of the contrasts for the fixation times on word $n+1$ resulted in significant effects (all $p \mathrm{~s}>.05$ ).

(Manuscript received September 20, 2007; revision accepted for publication March 24, 2008.) 